\title{
EFFECT OF PRESSURE ON THE DIELECTRIG PROPERTIES OF ICE Ih SINGLE CRYSTALS DOPED WITH $\mathrm{NH}_{3}$ AND HF
}

\author{
By M. Hubmann* \\ (Laboratorium für Festkörperphysik, Eidg. Technische Hochschule Zürich, CH-8o49 \\ Zürich, Switzerland)
}

\begin{abstract}
This paper describes measurements of the dielectric constant and of the conductivity on pure and doped ice single crystals subjected to hydrostatic pressure. The dopants used were $\mathrm{NH}_{3}$ $\left(c_{\mathrm{NH}_{3}} \approx 5 \times 10^{-5}\right.$ to $\left.1.2 \times 10^{-4} \mathrm{~mol} / \mathrm{l}\right)$ or $\mathrm{HF}\left(c_{\mathrm{HF}}=5 \times 10^{-6}\right.$ and $\left.5 \times 10^{-4} \mathrm{~mol} / \mathrm{l}\right)$. The pressure and temperature ranges covered were $\mathrm{I}$ to $\mathrm{I} 500$ bar and -15 to $-60^{\circ} \mathrm{C}$. The activation volumes for the orientational and the ionic contribution to the conductivity could be determined. A definitive interpretation is not possible because many questions concerning the formation of the defects are still open. In addition to the main subject, some new data from conductivity measurements on $\mathrm{NH}_{3}$-doped single crystals at atmospheric pressure are presented.

RÉsumé. Effet de la pression sur les propriétés de la glace Ih dopée à $\mathrm{NH}_{3}$ et à $\mathrm{HF}$. Ce travail décrit des mesures de la constante diélectrique et de la conductivité, effectuées sur des monocristaux de glace pure et dopée. Le dopage est fait avec $\mathrm{NH}_{3}\left(c_{\mathrm{NH}_{3}} \approx 5 \times 10^{-5} \ldots \mathrm{I}, 2 \times 10^{-4} \mathrm{M}\right)$ ou HF $\left(c_{\mathrm{HF}}=5 \times 10^{-6}\right.$ et $\left.5 \times 10^{-4} \mathrm{M}\right)$. Les domaines de pression et de température varient entre $\mathrm{I}$ et $\mathrm{I} 500$ bar et entre $-\mathrm{I}_{5}$ et $-60^{\circ} \mathrm{C}$. La volume d'activation a pu être déterminé autant pour les composants de réorientation que pour les composants ioniques. Une interprétation finale n'est pas possible, car plusieurs questions concernant la génération des défauts restent posées. Par ailleurs, quelques nouvelles valeurs de conductivité sont présentées; elles ont été mesurées à pression atmosphérique sur des monocristaux dopés à $\mathrm{NH}_{3}$.
\end{abstract}

Zusammenfassung. Effekt von Druck auf die dielektrischen Eigenschaften von $\mathrm{NH}_{3}$ - und HF-dotiertem Eis Ih. Diese Arbeit beschreibt Messungen der Dielektrizitätskonstanten und der Leitfähigkeit an reinen und dotierten Eis-Einkristallen unter hydrostatischem Druck. Dotiert wurde mit $\mathrm{NH}_{3}\left(c_{\mathrm{NH}_{3}} \approx 5 \times \mathrm{IO}^{-5} \ldots \mathrm{I}_{2} \times \mathrm{IO}^{-4}\right.$ $\mathrm{mol} / \mathrm{l})$ oder $\mathrm{HF}\left(c_{\mathrm{HF}}=5 \times \mathrm{IO}^{-6}\right.$ und $\left.5 \times \mathrm{IO}^{-4} \mathrm{~mol} / \mathrm{l}\right)$. Die überstrichenen Druck- und Temperaturbereiche I ... I 500 bar und $-15 \ldots-60^{\circ} \mathrm{C}$. Das Aktivierungsvolumen konnte sowohl für die Reorientierungs- als auch für die ionische Komponente der Leitfähigkeit bestimmt werden. Eine endgültige Interpretation ist nicht möglich, da manche Fragen über die Erzeugung der Fehlstellen noch offen sind. Zusätzlich zum Hauptthema werden einige neue Resultate von Leitfähigkeitsmessungen an $\mathrm{NH}_{3}$-dotierten Einkristallen bei Atmosphärendruck vorgelegt.

\section{INTRODUCTION}

The dielectric relaxation and the conductivity of hexagonal ice have been successfully interpreted by means of some specific types of defects, namely orientational defects and ions (Bjerrum, I95I; Gränicher, I958; Jaccard, I959 and I964). No very specific properties of these defects need be postulated to give a qualitative interpretation for a great amount of experimental data (Steinemann, 1957; Gross, 1965). Based on the same assumptions the author (Hubmann, in press, unpublished) was able to show, that a universal relation between electrical parameters can be derived from the theory. It is valid for all crystals within the region where the phase Ih exists. Experimental data from pure ice and ice doped with $\mathrm{HF}$ and $\mathrm{NH}_{3}$ within a very large range of concentration, temperature and pressure fulfil this relation very well. Such agreement gives confidence in the validity of the model on which the procedure is based and enables exclusion of competing ones, e.g. the one given by Von Hippel (I97I).

These manipulations, although revealing very astonishing properties of the system, are unsuitable for determining details of the formation and transfer mechanisms in the lattice. Such insights into the molecular details can be obtained from the study of the influence which pressure exerts on the electrical properties. The first work in this direction was done by Chan and others (1965), who made such experiments with pure ice. From this work valuable conclusions can be drawn. Gränicher (1969[b]) proposed pressure experiments using doped * Present address: Technisch-Chemisches Laboratorium ETH, Universitätstrasse 6, CH-8og2 Zürich,
Switzerland. 
single crystals, which enable more information on the dynamic properties of the electrically active defects to be obtained. Some preliminary measurements on HF-doped crystals have been published already (Taubenberger and others, 1973). This paper represents a further step in the programme devised by Gränicher.

\section{Experimental}

\section{I. Sample preparation; measuring cell}

The crystal growth and the determination of the dopant concentration was done by J. Bilgram. The $\mathrm{NH}_{3}$-doped crystals were produced by the Czochralski method (Bilgram, I973), the HF-doped and the pure crystals by zone melting (Bilgram and others, I973). The samples were shaped to roughly the desired dimensions on a lathe and then the two electrode faces cut plane and parallel by means of a microtome. Impurities which might have settled on the crystal faces during the treatment were removed by sublimation in the vacuum of the evaporation plant for 5 to $\mathrm{ro} \min$ at a temperature of $-10^{\circ} \mathrm{C}$. This procedure removed about 0.1 to $0.15 \mathrm{~mm}$ of the crystal on each side, so the parts of the crystal disturbed by the cutting were eliminated to a large extent. The crystal thus cleaned on the surface was then cooled down to the temperature of boiling nitrogen and at this temperature both electrode faces were covered with gold by evaporation. After gold plating, the crystal was warmed up to the cold-room temperature of $-\mathrm{I}_{5}^{\circ} \mathrm{C}$ over a period of $5 \mathrm{~h}$. On one side the gold electrode was divided into a central electrode and a guard ring by cutting a groove into the surface. After this treatment the crystal was placed in a tight "Teflon" (polytetrafluorethylene) box. The empty space was filled with high-purity silicone oil or heptane which served as pressuretransmitting medium. This measure suppressed sublimation which would have caused the evaporated layer to peel off. When a doped sample was in the box, the fluid contained a certain amount of dopant which prevented losses of $\mathrm{NH}_{3}$ or $\mathrm{HF}$ through diffusion.

The $\mathrm{NH}_{3}$ samples were prepared immediately after termination of the Czochralsky growth procedure. The HF samples were worked out of large ice pieces with an age of several months.

The samples were single crystal discs of $45 \mathrm{~mm}$ diameter and 6 to $8 \mathrm{~mm}$ thickness. The guarded electrode was about $20 \mathrm{~mm}$ in diameter and the gap between guard ring and centre electrode was 0.4 to $0.8 \mathrm{~mm}$.

The concentration of the dopant was determined after the measurements by melting the sample and analysing the concentration with ion-selective glass electrodes.

The "Teflon" box (Fig. I(a)) served as both measuring cell and storing vessel. Goldplated bronze leaf springs provide contact to the guard ring, which is on the top side in Figure $\mathrm{I}(\mathrm{a})$, and to the unguarded electrode. The contact force was 0.2 to $0.4 \mathrm{~N}$. The bottom of the box forms a membrane of $0.7 \mathrm{~mm}$ thickness which enables transmission of the pressure into the interior.

The box is supplied with SMC coaxial connectors which made storage and measurements in different types of device possible without removing the crystal from its environment.

\subsection{Suppression of the out-diffusion}

With the sample dimensions used, about $50 \%$ of the $\mathrm{NH}_{3}$ as well as of the $\mathrm{HF}$ is lost within $24 \mathrm{~h}$ when stored in free air. The fluid in the measuring cell is, therefore, enriched appropriately with the dopant to suppress the diffusion losses. In this way the crystal can be kept stable to the degree that the concentration-dependent low-frequency conductivity stays constant within a few per cent for several weeks. Before the crystal is measured for the first time, it is stored in the box at $-15^{\circ} \mathrm{C}$ for several days. This removes the inhomogeneity introduced during the preparation time of about $7 \mathrm{~h}$, and an equilibrium between crystal and enriched fluid is reached. 


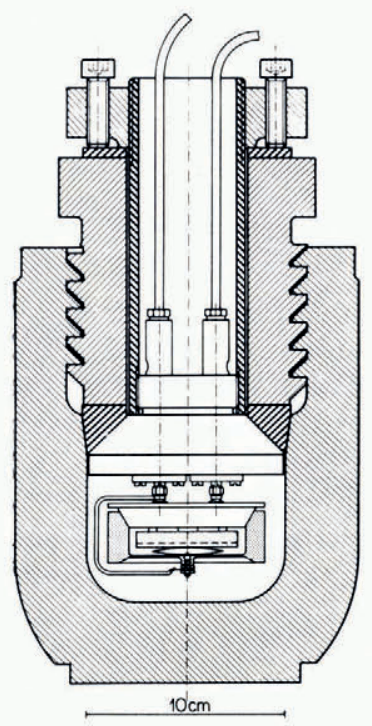

a)

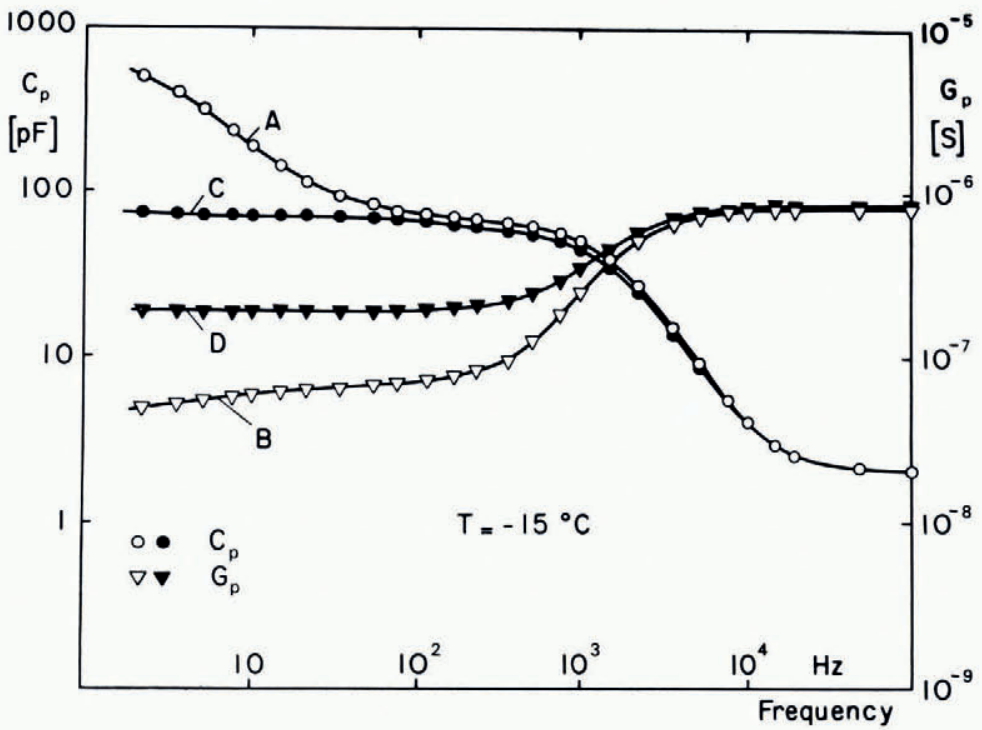

b)

Fig. I. (a) Measuring cell. During measurements, the pressure vessel is immersed in a bath of ethanol kept at constant temperature. (b) Dispersion of an inhomogeneously doped ice crystal. For explanation of the lettering on the curves see text.

The achievement of the method described above can be seen from Figure $\mathrm{I}(\mathrm{b})$. Curves A, B give the dispersion of $C_{\mathrm{p}}$ and $G_{\mathrm{p}}$ of an $\mathrm{NH}_{3}$-doped crystal about $20 \mathrm{~h}$ after termination of the growth process. The fluid was pure silicone oil, so out-diffusion was possible. Even after $\mathrm{I}$ oo $\mathrm{h}$, the diffusion was still going on as was indicated by the still decreasing $G_{\mathrm{p}}$ at low frequencies. At this stage the low-frequency increase of $C_{\mathrm{p}}$ was reduced a little. The fluid was finally replaced by fluid containing $\mathrm{NH}_{3}$. I $20 \mathrm{~h}$ after the exchange the $G_{\mathrm{p}}$ dispersion reached a stationary state and the curves C, D were measured. Obviously the crystal has regained so much $\mathrm{NH}_{3}$ that the low-frequency conductivity exceeds the initial value. Only a small part of the additional low-frequency dispersion remained.

The initial concentration, measured using ice pieces from parts close to the sample in the same single crystal, was $4 \times 10^{-6} \mathrm{~mol} / 1$, the final concentration (after the measurement of curves $\mathrm{C}$ and $\mathrm{D}$ in Figure $\mathrm{I}(\mathrm{b})) 9 \times \mathrm{IO}^{-6} \mathrm{~mol} / \mathrm{l}$.

It is quite obvious that the low-frequency dispersion is caused by dopant inhomogeneity. For HF-doped crystals this effect has not been investigated but a similar behaviour is expected when crystals are kept in doped fluid.

\subsection{Measurement of sample impedance}

The impedance of the sample was measured as a function of frequency in the range $\mathrm{I} \mathrm{Hz}$ to $100 \mathrm{kHz}$. In the frequency range of $200 \mathrm{~Hz}$ to $100 \mathrm{kHz}$ a General Radio type I6 I5-A capacitance bridge was used. The measurements in the low-frequency range $\mathrm{I} \mathrm{Hz}$ to $\mathrm{I} \mathrm{kHz}$ were made with a version of the bridge described by Berberian and Cole ( 1969 ). Both bridges had an accuracy of better than $\mathrm{I} \%$.

In general the measurements were made with a voltage of $0.6 \mathrm{~V}$ amplitude across the sample. At this voltage, no voltage dependence of the impedance was observed with highly 
doped crystals. Lightly doped and pure crystals showed voltage dependence in the lowfrequency region which made a reduction of the measuring voltage necessary. Measurements were possible down to $50 \mathrm{mV}$.

\section{Numerical procedures}

\section{I. Evaluation of dispersion parameters}

The sample impedance $Z$ is given by the two bridge readings $C_{\mathrm{p}}$ and $G_{\mathrm{p}}$ according to the defining formula

$$
\mathrm{I} / Z=G_{\mathrm{p}}+i \omega C_{\mathrm{p}}
$$

which corresponds to a parallel equivalent circuit. The raw data $G_{\mathrm{p}}$ and $C_{\mathrm{p}}$ are proportional to the conductivity $\sigma$ and to the dielectric constant $\epsilon$ respectively. For the case where the dispersion is a Debye dispersion with a single relaxation time, the plot $C_{\mathrm{p}}$ versus $G_{\mathrm{p}}$ forms a straight line whose end points are given by $\left(G_{0}, C_{\mathrm{s}}\right)$ and $\left(G_{\infty}, C_{\infty}\right)$ (Gränicher, I969[a]). The quantities in the brackets represent the limiting values of $C_{\mathrm{p}}$ and $G_{\mathrm{p}}$ at low and high frequency respectively. All samples reported in this work fulfil this linear relationship quite well. Additional dispersion regions appear as deviations at the ends of the line. Figure 2 (a) shows as an example a plot of the dispersion curves c, D from Figure $\mathrm{I}(\mathrm{b})$. In the low-frequency region the conductivity is affected only to a small extent by the extra dispersion. The limiting value $G_{0}$ can therefore easily be determined. When $G_{0}$ is known, $C_{\mathrm{s}}$ can be determined from the plot of $C_{\mathrm{p}}$ versus $G_{\mathrm{p}}$ as shown in Figure 2(a). Highly doped crystals show, in certain cases, a downward deviation at low frequencies. Here too the procedure described above is used.

\subsection{Separation of the conductivities $\sigma_{0}$ and $\sigma_{\infty}$ into the orientational and ionic part}

According to Jaccard's (I964) theory the conductivities $\sigma_{\infty}$ and $\sigma_{0}$ can be expressed in terms of the conductivities $\sigma_{\mathrm{DL}}$ and $\sigma_{ \pm}$attributed to the orientational and the ionic defects respectively.

$$
\begin{gathered}
\sigma_{\infty}=\sigma_{ \pm}+\sigma_{\mathrm{DL}}, \\
\frac{e^{2}}{\sigma_{0}}=\frac{e_{ \pm}^{2}}{\sigma_{ \pm}}+\frac{e_{\mathrm{DL}}^{2}}{\sigma_{\mathrm{DL}}} .
\end{gathered}
$$

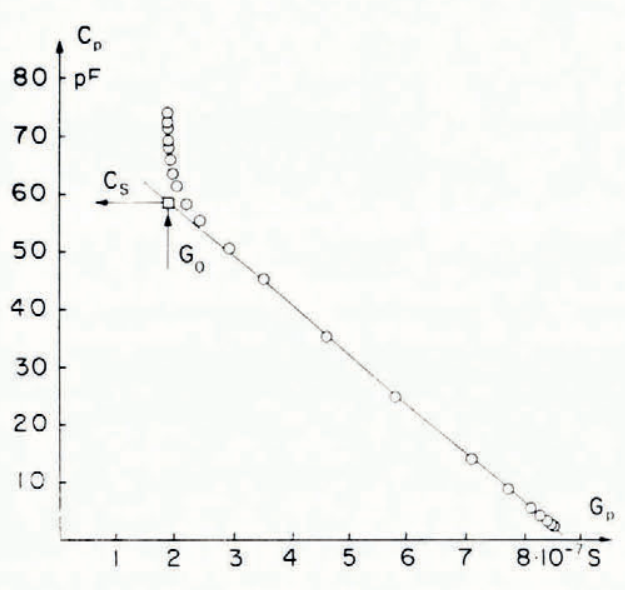

a)

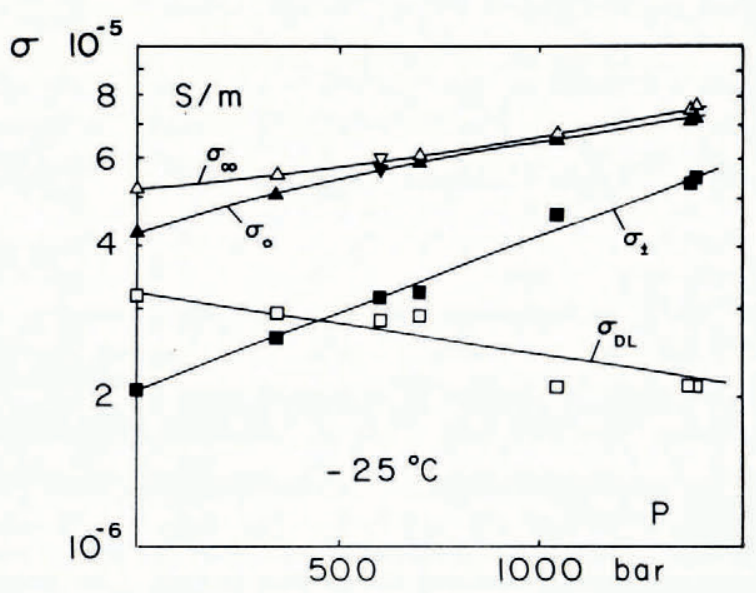

b)

Fig. 2. (a) Determination of the limiting value $C_{\mathrm{s}}$ when an additional low-frequency dispersion is present. $C_{\mathrm{p}}$ and $G_{\mathrm{p}}$ are proportional to the dielectric constant $\epsilon$ and to the conductivity $\sigma$ respectively. (b) Separation of conductivities into orientational and ionic contribution. The example is taken from Figure 4. 
As long as one of the two quantities $\sigma_{ \pm}$or $\sigma_{\mathrm{DL}}$ is small compared to the other, one of them can be neglected in the expression for $\sigma_{0}$ and $\sigma_{\infty}$, and the determination of the components is simple. When the components are of similar order of magnitude, as is the case with doped crystals, a more refined procedure is necessary. The two equations above can be solved for $\sigma_{\mathrm{DL}}$ and $\sigma_{ \pm}$giving the following set of formulae

where

$$
\sigma_{\mathrm{DL}}=\sigma_{\infty} /(\mathrm{I}+\rho) ; \quad \sigma_{ \pm}=\sigma_{\infty} \rho /(\mathrm{I}+\rho),
$$

with

$$
\rho=\frac{\sigma_{ \pm}}{\sigma_{\mathrm{DL}}}=\frac{B \pm\left(B^{2}-4 s^{2}\left(e_{ \pm} / e_{\mathrm{DL}}\right)^{2}\right)^{\frac{1}{2}}}{2 s}
$$

$$
B=\left(\mathrm{I}+e_{ \pm} / e_{\mathrm{DL}}\right)^{2}-s\left(\mathrm{I}+e_{ \pm}^{2} / e_{\mathrm{DL}^{2}}\right) ; \quad s=\sigma_{0} / \sigma_{\infty} .
$$

The ratio of the effective charges has been determined by the author (Hubmann, unpublished) with the result $e_{ \pm} / e_{\mathrm{DL}}=\mathrm{I} .63 \pm 2 \%$. When the ions are dominant the + sign is to be used in the formula for $\rho$, and vice versa. Which of the two possibilities is present is clear in most cases. In the vicinity of the crossover $\left(\sigma_{0} / \sigma_{\infty}>0.9\right)$ care must be taken in using this method. Inhomogeneities prevent the values $\sigma_{0} / \sigma_{\infty}=\mathrm{I}$ being reached leading to faulty interpretation. In addition to this, a superimposed low-frequency dispersion can similarly lead to erroneous conclusions. Figure 2 (b) shows the result of the separation procedure just described. It looks rather convincing.

\section{Results on $\mathrm{NH}_{3}$-DOped ice}

As a working hypothesis, it is assumed that the $\mathrm{HF}$ and $\mathrm{NH}_{3}$ dopant molecules replace substitutionally $\mathrm{H}_{2} \mathrm{O}$ molecules and introduce in this way L-defects or D-defects respectively into the lattice in addition to the intrinsic defects. They also may undergo ionization producing ionic defects.

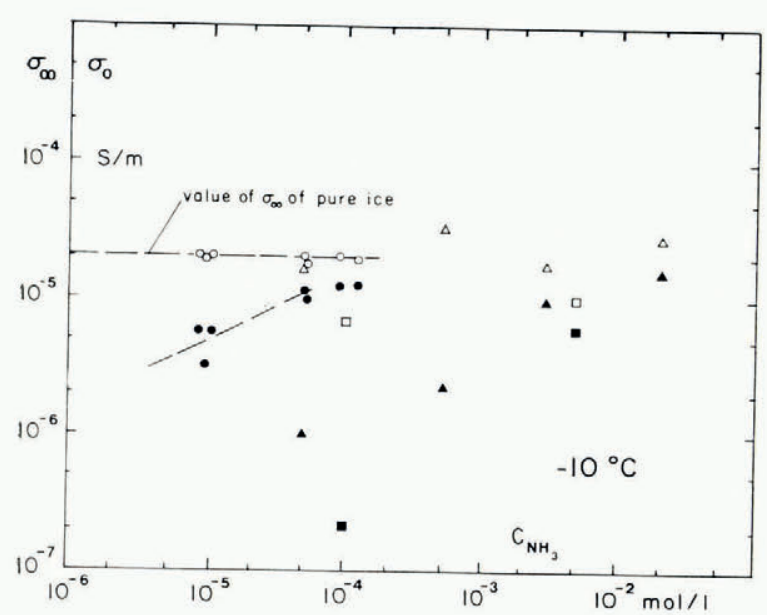

a)

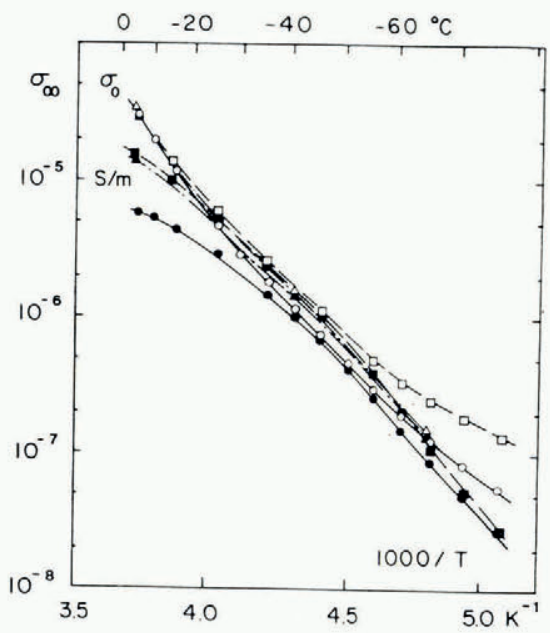

b)

Fig. 3

(a) Concentration dependence of high- (open signs) and low-frequency (closed signs) conductivity.

(b) Temperature dependence of high- and low-frequency conductivity of single crystals doped with $\mathrm{NH}_{3} . \bigcirc \mathrm{CHH}_{3}=8 \times \mathrm{Io} \mathrm{O}^{-6}$, $\Delta c_{\mathrm{NH}_{3}}=5 \times \mathrm{IO}^{-5}, \square c_{\mathrm{NH}_{3}}=1.2 \times \mathrm{IO}^{-4} \mathrm{~mol} / \mathrm{l}$. Meaning of full and open signs as in $(a)$. 
Investigations of HF-doped ice are quite numerous (Steinemann, 1957; Gross, I965; Camplin and Glen, 1973; Von Hippel and others, 1972). But on $\mathrm{NH}_{3}$-doped ice there are only few (Levi and Lubart, I96r ; Arias and others, I966), since it is difficult to get sufficient amounts of $\mathrm{NH}_{3}$ into the lattice. This difficulty has been surmounted by Bilgram. A short account of the results on $\mathrm{NH}_{3}$-doped ice is given here for this reason.

The concentration dependence of the conductivities is given in Figure $3(\mathrm{a})$. This figure shows large discrepancies compared with data from polycrystalline samples. One striking feature is that the high-frequency conductivity is not influenced by doping, meaning that the intrinsic population of orientational defects is not affected. A similar behaviour is found in the temperature dependence (Fig. $3(\mathrm{~b})$ ). In the temperature range around $-45^{\circ} \mathrm{C}$ a remarkable parallelism of the conductivities occurs.

To conclude this brief review it should be mentioned that, in contrast to Arias and others (1966), only small additional low-frequency dispersion is observed. As is discussed in Section 2 above, this phenomenon is due to inhomogeneity. The absence of this dispersion in our crystals can thus be taken as an indication of homogeneous $\mathrm{NH}_{3}$ distribution.

\section{Results of measurements from ice Under PRESSURE}

\subsection{General}

Figure 4 presents the conductivities $\sigma_{\infty}, \sigma_{0}$ and the static dielectric constant $\epsilon_{\mathrm{S}}$ as a function of pressure as measured at various temperatures. At atmospheric pressure the crystal under consideration had a conductivity crossover at about $-45^{\circ} \mathrm{C}$. At $-15^{\circ} \mathrm{C}$ the crystal is in the domain where the orientational defects dominate but it is already close to the crossover. Increasing pressure increases the ionic conductivity and decreases the orientational conductivity. Thus the crystal is shifted toward the crossover. This change is also indicated by a
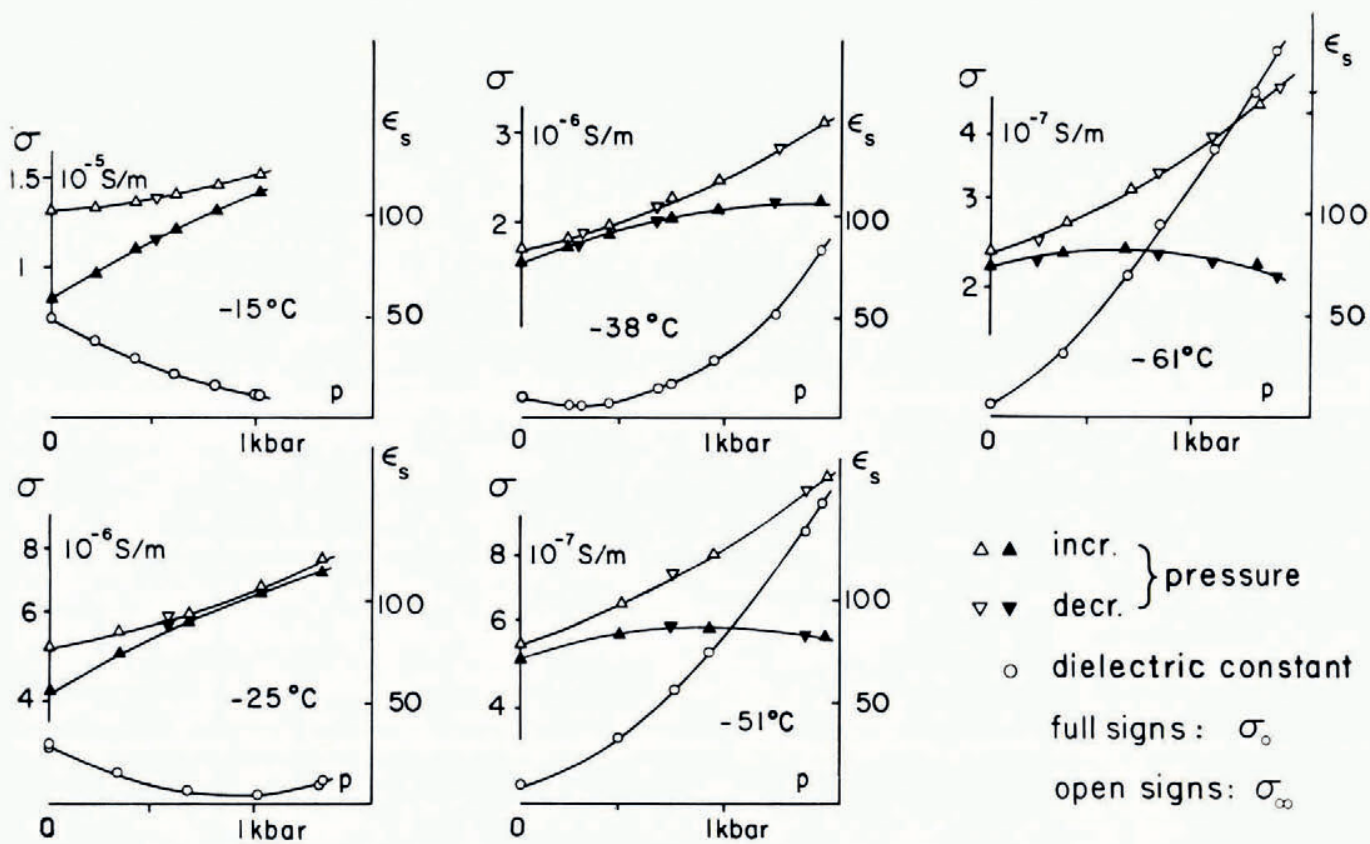

full signs: $\sigma_{\circ}$ open signs: $\sigma_{\infty}$

Fig 4. Pressure dependence of the conductivities $\sigma_{0}, \sigma_{\infty}$ and of the dielectric constant $\epsilon_{\mathrm{s}}$ at various temperatures. Ice single crystals $\mathrm{c}_{\mathrm{NH}_{3}}=5 \times \mathrm{IO}^{-5} \mathrm{~mol} / \mathrm{l}$. Field parallel to c-axis. The scales are linear for pressure and for dielectric constant and logarithmic for the conductivities. 
decrease in $\epsilon_{\mathrm{s}}$. When the conductivities $\sigma_{\infty}$ and $\sigma_{0}$ are close enough, as is the case at $-25^{\circ} \mathrm{C}$ and $-35^{\circ} \mathrm{C}$, it is possible to shift the system across the crossover by pressure. At $-5^{\mathrm{I}}$ and $-6 \mathrm{I}^{\circ} \mathrm{C}$ the ionic regime is already reached at atmospheric pressure. Now pressure induces a shift deeper into the ionic domain. It is remarkable that values for $\epsilon_{\mathrm{S}}$ of more than $\mathrm{I} 8 \mathrm{o}$ can be reached. It is interesting to note here that the behaviour under pressure also follows the universal relation mentioned in the Introduction.

It is clear that a direct interpretation of the pressure dependence of the two measured quantities $\sigma_{\infty}$ and $\sigma_{0}$ is not possible. Both conductivities consist of two components which are comparable in magnitude. Therefore decomposition into $\sigma_{\mathrm{DL}}$ and $\sigma_{ \pm}$according to the procedure described in Section 3.2 gives better insight as is obvious from Figure 2(b). For this reason the behaviour of the derived quantities $\sigma_{\mathrm{DL}}$ and $\sigma_{ \pm}$as a function of pressure is discussed in the following.

\subsection{Temperature dependence of the activation volume}

The pressure dependence is usually discussed in terms of the activation volume

$$
\Delta V_{i}=-\frac{R T}{\sigma_{i}} \frac{\mathrm{d} \sigma_{i}}{\mathrm{~d} p}, \quad i=\mathrm{DL}, \pm .
$$

Because $\ln \left(\sigma_{i}\right)$ depends linearly on the pressure (see Fig. 2(b)), this is an adequate description. Figure $5(\mathrm{a})$ gives a summary of the data obtained. The activation volume of the ionic conductivities is negative, that of the orientational conductivities positive. A small temperature dependence exists.

Some $\mathrm{NH}_{3}$-doped crystals $\left(c_{\mathrm{NH}_{3}}=5 \times \mathrm{IO}^{-5}\right.$ and $\left.\mathrm{I} .2 \times \mathrm{IO}^{-4} \mathrm{~mol} / \mathrm{l}\right)$ show, at low temperatures, no linear relation between $\ln \left(\sigma_{\mathrm{DL}}\right)$ and pressure. In this case approximate values for the activation volumes at $p \approx \mathrm{I}$ bar and for $p \approx \mathrm{I}$ kbar are given and the temperature dependence is indicated by the dashed lines. Because there are not enough measurements available it is not possible to decide whether this expresses a systematic trend or only an individual deviation of a peculiar crystal. The second possibility appears to be more likely.

\subsection{Activation volumes as a function of doping}

A survey of activation volumes versus the concentration is given in Figure 5 (b). The scales for the $\mathrm{NH}_{3}$ and $\mathrm{HF}$ concentrations have been chosen in a way that, roughly speaking, the concentrations of $\mathrm{H}_{3} \mathrm{O}^{+}$and L-defects increase when going from left to right and the concentrations of $\mathrm{OH}^{-}$and D-defects decrease. To give an idea about the type of defect dominant, the approximate position of the crossovers (I, II) have been estimated and indicated on the diagram.

\section{Discussion}

\section{I. Scheme of interpretation}

Because there are two species of orientational defects and two species of ions, the conductivities $\sigma_{\mathrm{DL}}$ and $\sigma_{ \pm}$can be split once again into two different terms

$$
\begin{aligned}
\sigma_{\mathrm{DL}} & =\sigma_{\mathrm{L}}+\sigma_{\mathrm{D}}=e_{\mathrm{DL}} n_{\mathrm{L}} u_{\mathrm{L}}+e_{\mathrm{DL}} n_{\mathrm{D}} u_{\mathrm{D}}, \\
\sigma_{ \pm} & =\sigma_{+}+\sigma_{-}=e_{ \pm} n_{+} u_{+}+e_{ \pm} n_{-} u_{-} .
\end{aligned}
$$

In these expressions $e_{\mathrm{DL}}, e_{ \pm}$are the effective charges, $n_{i}$ the defect concentrations, and $u_{i}$ the mobilities. In many cases one of the two terms in Equations (2) and (3) is so small it can be neglected, simplifying the discussion. The pressure dependence of each term is written as follows: 


$$
\begin{aligned}
\frac{\mathrm{I}}{\sigma_{i}} \frac{\mathrm{d} \sigma_{i}}{\mathrm{~d} p} & =\frac{\mathrm{I}}{e_{i}} \frac{\mathrm{d} e_{i}}{\mathrm{~d} p}+\frac{\mathrm{I}}{n_{i}} \frac{\mathrm{d} n_{i}}{\mathrm{~d} p}+\frac{\mathrm{I}}{u_{i}} \frac{\mathrm{d} u_{i}}{\mathrm{~d} p} \\
& =\frac{\mathrm{I}}{e_{i}} \frac{\mathrm{d} e_{i}}{\mathrm{~d} p}-\frac{\Delta V_{i}^{\mathrm{f}}}{R T}-\frac{\Delta V_{i}^{\mathrm{t}}}{R T} .
\end{aligned}
$$

The magnitude of the first term is small, of the order of the linear compressibility, and can therefore be neglected for a qualitative consideration. The second term reflects the influence of pressure on the "quasi-chemical" processes (dissociation and recombination) by which the defects are formed. Finally, the third term gives the pressure dependence of the kinetics of an elementary displacement step. From this it is obvious that the pressure coefficient defined by Equation ( $\mathrm{I}$ ) is caused by two contributions which are different in nature. A more detailed discussion of the elementary processes and some estimates on the values to be expected can be found in the paper by Chan and others (1965). Based on certain assumptions on the defect chemistry, Gränicher ( $1969[\mathrm{~b}]$ ) devised a programme using measurements on doped ice which makes it possible to determine the activation volumes of each defect separately.
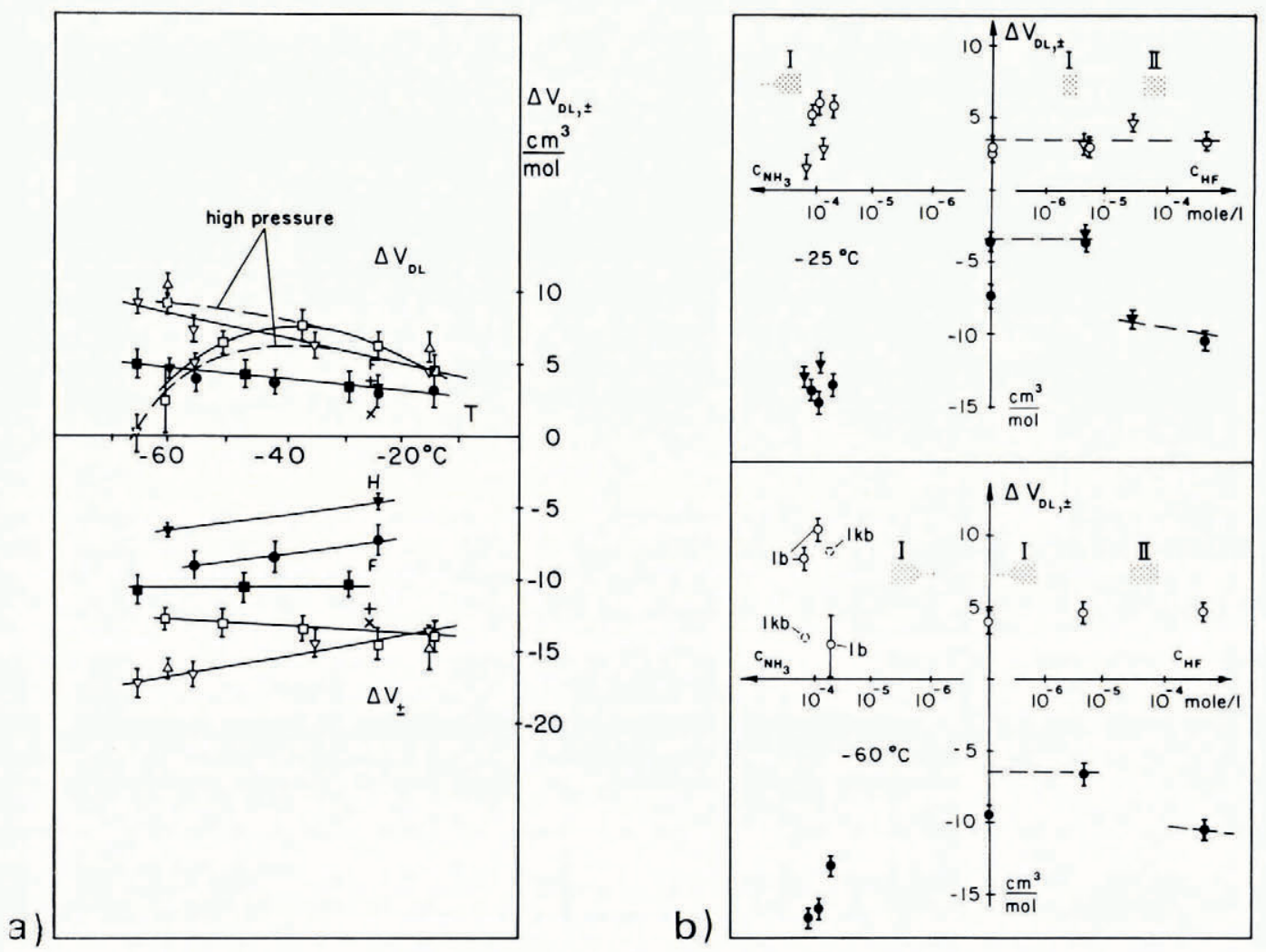

Fig. 5. (a) Activation volumes of $\sigma_{\mathrm{DL}}$ and $\sigma_{+} . \Delta V_{\mathrm{DL}}$ are positive, $\Delta V_{ \pm}$negative. The doping concentrations (in mol $l$ l) and the pressure-transmitting fluid used were: $\nabla c_{\mathrm{NH}_{3}}=I .2 \times \mathrm{IO}^{-4}$, Heptane $+\mathrm{NH}_{3} ; \triangle \mathrm{cNH}_{3}=9 \times \mathrm{IO}^{-5}, \mathrm{Heptane}^{-}$ $\mathrm{NH}_{3} ; \square c_{\mathrm{NH}_{3}}=5 \times \mathrm{IO}^{-5}$, silicone oil $+\mathrm{NH}_{3} ;$ pure, Heptane; $c_{\mathrm{HF}}=4.5 \times 10^{-4}$, Heptane $+\mathrm{HF} ; \nabla c_{\mathrm{HF}}=$ $5 \times 10^{-6}$, Heptane $+\mathrm{HF} ; \times c_{\mathrm{NH}_{3}} \approx 1.5 \times 10^{-4} ;+c_{\mathrm{NH}_{3}} \approx 8 \times 10^{-5} ; \mathrm{F} c_{\mathrm{HF}} \approx 3 \times 10^{-5} ; \mathrm{H} c_{\mathrm{HF}} \approx 5 \times 10^{-6}$. The last four samples in this sequence were measured in pure silicone oil. (b) Activation volumes at various concentrations. Open signs $\Delta V_{\mathrm{DL}}$, full signs $\Delta V_{ \pm} . \nabla \nabla$ represent data from measurements in pure transmission fluids. They are on this ground inhomogeneously doped and their concentration must therefore be taken as very approximate. 


\subsection{Orientational conductivity}

From what has been said it is very surprising to see from Figure 5 (b) that the activation volume of $\sigma_{\mathrm{DL}}$ is almost indifferent to doping concentration as well as to the doping species. In the region largely comprising the interval below and somewhat across the first crossover I the orientational defects are intrinsic. At $-25^{\circ} \mathrm{C}$ this region is given by $c_{\mathrm{HF}} \leqslant \mathrm{IO}^{-5} \mathrm{~mol} / \mathrm{l}$ or $c_{\mathrm{NH}_{3}} \leqslant \mathrm{IO}^{-4} \mathrm{~mol} / \mathrm{l}$. Here $\sigma_{\mathrm{DL}}$ contains a term which describes the influence of pressure on the dissociation of two bonds into a L- and D-defect by a molecular rotation,

$$
{ }_{2} \mathrm{~B} \rightleftharpoons \mathrm{L}+\mathrm{D} \text {. }
$$

In the region beyond the second crossover II (in HF-doped crystals), on the other hand, the L-defects are extrinsic. One can write $n_{\mathrm{L}}=c_{\mathrm{HF}}$, so the term $\left(\mathrm{I} / n_{\mathrm{L}}\right) \mathrm{d} n_{\mathrm{L}} / \mathrm{d} p$ from the defect generation Equation (4) is zero. The pressure dependence is therefore determined by the term $\Delta V_{i}{ }^{\mathrm{t}}$ alone, so one expects in this region a value of $\Delta V_{\mathrm{DL}}$ which is different from the one in the intrinsic region. The discrepancy becomes more pronounced if one takes into account that $\sigma_{\mathrm{D}}$ can be dropped in Equation (2) for pure and HF-doped ice because $u_{\mathrm{D}}<u_{\mathrm{L}}$ for structural reasons. From the measurements one must thus tentatively conclude that Reaction (5) is independent of pressure. How far $\Delta V_{\mathrm{DL}^{\mathrm{f}}}{ }^{\mathrm{f}}=\mathrm{o}$ can be brought into agreement with considerations given by Chan and others (1965) is left open.

The indifference of $\Delta V_{\mathrm{DL}}$ on doping allows also a conclusion on the defect interaction proposed by Bilgram and Gränicher (I974) postulating mobile $\mathrm{H}_{3} \mathrm{O}^{+} \cdot \mathrm{L}$ aggregates. In the region between the crossovers I and II, L-defects are in the minority. Their number is controlled by the dissociation of aggregates

$$
\mathrm{H}_{3} \mathrm{O}^{+} \cdot \mathrm{L} \rightleftharpoons \mathrm{H}_{3} \mathrm{O}^{+}+\mathrm{L} \text {. }
$$

As consequence of this, one expects a value for $\Delta V_{\mathrm{DL}}$ which differs from those in the intrinsic and in the extrinsic regions. Whether pressure-independence of the reaction (6) can be proposed is even more questionable than for (5).

On the $\mathrm{NH}_{3}$ side the reasoning is different. As a result of the conductivity measurements it follows that $\sigma_{\mathrm{DL}}$ is not affected up to concentrations of $\mathrm{IO}^{-4} \mathrm{~mol} / \mathrm{l}$, which means that the intrinsic region extends to this concentration. At lower temperature an increase of activation volume is observed.

\subsection{Ionic conductivity}

Fewer problems are encountered with the ionic conductivity, because there one finds the variations in $\Delta V_{ \pm}$necessary for an explanation. The intrinsic concentration of the ions is so small that even small amounts of impurities are sufficient to bring the crystal into the extrinsic state. The activation volume remains constant for small and medium HF concentrations. The value of $-7 \mathrm{~cm}^{3} / \mathrm{mol}$ in the diagram for pure ice was obtained from a sample with extremely low $\sigma_{0}$. From measurements of Camplin and Glen (1973) it is known that there exists a concentration range where $\sigma_{0}$ is proportional to the concentration of $\mathrm{HF}$. This corresponds to a full dissociation of $\mathrm{HF}$ according to

$$
\mathrm{HF}+\mathrm{H}_{2} \mathrm{O} \rightleftharpoons \mathrm{F}^{-}+\mathrm{H}_{3} \mathrm{O}^{+} .
$$

One has $n_{+} \approx c_{\mathrm{HF}}$ and $\left(\mathrm{r} / n_{+}\right) \mathrm{d} n_{+} / \mathrm{d} p \approx$ o.

At higher concentrations the dissociation is no longer complete, this is a necessary condition for the existence of a second crossover. Now $n_{+} \neq c_{\mathrm{HF}}$ and $\left(\mathrm{I} / n_{+}\right) \mathrm{d} n_{+} / \mathrm{d} p$ is controlled by the dissociation of HF. Hence in the range of incomplete dissociation the activation volume must change to another value as shown by Figure 5 (b).

In the $\mathrm{NH}_{3}$ case no unique explanation can be given at present because of a lack of data in the lower conductivity range. It is easy to see however, that similar arguments are valid. 


\subsection{Summary}

The discussion above shows that the interpretation is strongly based on the defect chemistry assumed. Sections 6.2 and 6.3 rely on assumptions developed by Steinemann, Gränicher, and Jaccard in the early sixties and also on the observed linear dependence of $\sigma_{0}$ on HF concentration (Camplin and Glen, r973). These do not allow for interactions of the defects to form aggregates and also suppose that dopants are built into the lattice by substituting $\mathrm{H}_{2} \mathrm{O}$ molecules. The discovery by Bilgram and Gränicher (1974), that these old assumptions lead to unexpected values for the mobility, gave a clear indication that the simple picture of the defect chemistry must be revised. The high diffusivities of HF (Haltenorth and Klinger, I969) and $\mathrm{NH}_{3}$ (Hubmann, I975) in ice also suggest that interstitial impurities, and eventually lattice distortions from dislocations, play a role. Therefore it can be seen that the problem of defect chemistry must be solved before reliable conclusions can be obtained from measurements of conductivities under pressure. The results from these experiments can nevertheless give valuable hints toward elucidation of the processes of defect formation and interaction.

\section{Acknowledgement}

I am greatly indebted to Professor H. Gränicher and to my colleagues Dr M. Gautschi and R. Taubenberger for many helpful suggestions. I wish to express my special thanks to Dr J. Bilgram, who grew the crystals and determined the doping concentrations, for his reliable collaboration. This work was supported by the Schweizerischer Nationalfonds zur Förderung der wissenschaftlichen Forschung.

\section{REFERENCES}

Arias, D., and others. I966. Electrical properties of ice doped with $\mathrm{NH}_{3}$, [by] D. Arias, L. Levi and L. Lubart. Transactions of the Faraday Society, Vol. 62, No. 523, p. 1955-62.

Berberian, J. G., and Cole, R. H. 1969. Low frequency bridge for guarded three-terminal and four-terminal measurements of admittance. Review of Scientific Instruments, Vol. 40, No. 6, p. 81 I-I 7.

Bilgram, J. H. 1973. Perfect highly doped ice crystals by the Czochralski method. (In Whalley, E., and others, ed. Physics and chemistry of ice: papers presented at the Symposium on the Physics and Chemistry of Ice, held in Ottawa, Canada, I4-I8 August 1972. Edited by E. Whalley, S. F. Fones, L. W. Gold. Ottawa, Royal Society of Canada, p. 246-50.)

Bilgram, J. H., and Gränicher, H. I974. Defect equilibria and conduction mechanisms in ice. Physics of Condensed Matter, Vol. 18, No. 4, p. 275-91.

Bilgram, J. H., and others. 1973. Perfection of zone refined ice single crystals, [by] J. [H.] Bilgram and H. Wenzl and G. Mair. Journal of Crystal Growth, Vol. 20, No. 4, p. 319-21.

Bjerrum, N. I95I. Structure and properties of ice. Kongelige Danske Videnskabernes Selskab. Matematisk-fysiske Meddelelser, Bd. $27, \mathrm{Nr}$. I.

Camplin, G. C., and Glen, J. W. 1973. The dielectric properties of HF-doped single crystals of ice. (In Whalley, E., and others, ed. Physics and chemistry of ice: papers presented at the Symposium on the Physics and Chemistry of Ice, held in Ottawa, Canada, I4-18 August 1972. Edited by E. Whalley, S. F. Jones, L. W. Gold. Ottawa, Royal Society of Canada, p. 256-6i.)

Chan, R. K., and others. I965. Effect of pressure on the dielectric properties of ice I, [by] R. K. Chan, D. W. Davidson and E. Whalley. Journal of Chemical Physics, Vol. 43, No. 7, p. 2376-83.

Gränicher, H. 1958. Gitterfehlordnung und physikalische Eigenschaften hexagonaler und kubischer Eiskristalle. Zeitschrift für Kristallographie, Bd. 1 10, Ht. 5-6, p. 432-71.

Gränicher, H. I969[a]. Evaluation of dielectric dispersion data. (In Riehl, N., and others, ed. Physics of ice: proceedings of the international symposium on physics of ice, Munich, Germany, September 9-14, 1968. Edited by $\mathcal{N}$. Riehl, B. Bullemer, H. Engelhardt. New York, Plenum Press, p. 527-33.)

Gränicher, H. $1969[\mathrm{~b}]$. On the interpretation of the pressure dependence of properties controlled by lattice defects. (In Riehl, N., and others, ed. Physics of ice: proceedings of the international symposium on physics of ice, Munich, Germany, September 9-14, 1968. Edited by N. Riehl, B. Bullemer, H. Engelhardt. New York, Plenum Press,

p. $534^{-40 .)}$
Gross, G. W. 1965. Ion incorporation and activation energies of conduction in ice. Annals of the New York Academy of Sciences, Vol. 125, Art. 2, p. 380-89.

Haltenorth, H., and Klinger, J. 1969 . Diffusion of hydrogen fluoride in ice. (In Riehl, N., and others, ed. Physics of ice: proceedings of the international symposium on physics of ice, Munich, Germany, September 9-14, 1968. Edited by N. Riehl, B. Bullemer, H. Engelhardt. New York, Plenum Press, p. 579-84.) 
Hubmann, M. 1975. Diffusion von Fremdsubstanz in Eis. Beispiel $\mathrm{NH}_{3}$. Helvetica Physica Acta, Vol. 48, Fasc. 4, p. $449-50$.

Hubmann, M. In press. Polarization processes in the ice lattice. I. Approach by thermodynamics of irreversible processes. New experimental verification by means of a universal relation. Zeitschrift für Physik, B.

Hubmann, M. Unpublished. Polarization processes in the ice lattice. [Dr. sc. nat. thesis, Eidgenössische Technische Hochschule Zürich, 1976. Available on request, Diss. ETH Nr. 5648.]

Jaccard, C. I959. Étude théorique et expérimentale des propriétés électriques de la glace. Helvetica Physica Acta, Vol. 32, Fasc. 2, p. 89-128.

Jaccard, C. 1964. Thermodynamics of irreversible processes applied to ice. Physik der kondensierten Materie, Bd. 3, Ht. 2, p. 99-1 18.

Levi, L., and Lubart, L. ${ }^{1} 961$. Conductivité électrique de la glace dopée de $\mathrm{NH}_{4} \mathrm{OH}$. Journal de Chimie Physique, Vol. 58 , No. 9, p. $86_{3}-68$.

Steinemann, A. 1957. Dielektrische Eigenschaften von Eiskristallen. II. Teil. Dielektrische Untersuchungen an Eiskristallen mit eingelagerten Fremdatomen. Helvetica Physica Acta, Vol. 30, Fasc. 7, p. 581-610.

Taubenberger, R., and others. I973. Effect of hydrostatic pressure on the dielectric properties of ice $I_{h}$ single crystals, [by] R. Taubenberger, M. Hubmann and H. Gränicher. (In Whalley, E., and others, ed. Physics and chemistry of ice: papers presented at the Symposium on the Physics and Chemistry of Ice, held in Ottawa, Canada, I4-18 August 1972. Edited by E. Whalley, S. 7. Jones, L. W. Gold. Ottawa, Royal Society of Canada, p. 194-98.)

Von Hippel, A. R. I97I. Transfer of protons through "pure" ice $I_{h}$ single crystals. II. Molecular models for polarization and conduction. Journal of Chemical Physics, Vol. 54, No. 1, p. 145-49.

Von Hippel, A. R., and others. 1972. Dielectric and mechanical response of ice $\mathrm{I}_{\mathrm{h}}$ single crystals and its interpretation, [by] A. [R.] Von Hippel, R. Mykolajewycz, A. H. Runck and W. B. Westphal. Fournal of Chemical Physics, Vol. 57, No. 6, p. 2560-71.

\section{DISGUSSION}

G. C. Camplin: Do you see your results substantiating a theory based upon Bjerrum defects and ionic defects or one which involves Bjerrum-ion aggregates?

M. Hubmann: The results obtained here confirm the formalism developed by Jaccard and are therefore interpreted in terms of that formalism. The formalism just mentioned starts from a minimum of assumptions, which are: (a) there are mobile defects, and (b) they change the configuration of the lattice while moving. Besides Bjerrum and ionic defects there are other defects having this property among which are vested vacancies and aggregates. So I would not stick too much to Bjerrum and ionic defects. Strictly speaking, this question is still open at present.

R. TAubenberger: As you have measurements now both for $\mathrm{NH}_{3}$ - and HF-doped crystals for large ionic majority, it should be possible to determine all the defects' activation volumes according to Gränicher's ( $1969[\mathrm{~b}]$ ) programme. Have you tried this and if so, is there anything conclusive?

Hubmann: In my paper I tried to show that such an interpretation leads to doubtful conclusions. This is because it is based on the origin and interaction of the defects assumed. It is this very field where the discussions are still going on as we have seen in the foregoing session. So a definitive evaluation of the quantities under consideration is not possible at present.

TAubenberger: Did you make sure by plotting the $\tau_{i}(\mathrm{I} / T)$ of the Debye dispersion and the adjacent ones that for lower temperatures and higher doping concentrations you are also in the so-called ionic branch dealing with the intrinsic dispersion region?

Hubmann: In none of my experiments did this form a problem, because dispersions of other origin than the orientational one were either largely absent or well separated in the frequency range. Sophisticated methods such as you suggest in your question were not necessary.

TAubenberger: The very large effect of pressure on the ionic branch shows that $p$ does not act on $\sigma_{0}$ in the way to be expected from the thermal activation of some ionic defect. Do you think that the pressure coefficient for $\sigma_{0}$ is measuring any sort of bulk property? 
Hubmann: It is quite correct that the activation volume of $\sigma_{ \pm}$, which is in many cases responsible for the behaviour of $\sigma_{0}$, is high; the physical significance of this is subject to a molecular interpretation. The behaviour of the quantity in question however is strictly in the form the Jaccard model requires. This can hardly be expected from a process other than a bulk property.

TAUBenBerger: You found that $\Delta V_{\mathrm{DL}}$ is approximately constant in the whole concentration region covering the passage of the first and second $\Delta \epsilon$ minimum. Would you not take this as a hint that $\sigma_{\infty}$ never lost its significance as being due to Bjerrum defects, in other words that you never passed a crossover in the sense of Jaccard's model at all, and that $\Delta \epsilon$ minima are just phenomenologically given by the proximity in values of two individually-acting conductivity mechanisms?

Hubmann: The absolute values of $\sigma_{\infty}$ and $\sigma_{0}$ give a clear indication whether the defects are intrinsic or extrinsic, from which conclusions on the character of the majority carriers can be drawn. In addition to this it is possible to compare my results with results from other work from which the positions of the $\Delta \epsilon$ minima can be determined. Finally the position of the measured values on the universal $\Lambda(s)$ representation allows an identification of the state. So when evaluating my results there was never any doubt which type of carrier is in the majority. 